\title{
GROWTH OF CZECH BREASTFED INFANTS IN COMPARISON WITH THE WORLD HEALTH ORGANIZATION STANDARDS
}

\author{
Jana Vignerová', Lenka Shriver², Markéta Paulová1, Marek Brabec ${ }^{3,4}$, Dagmar Schneidrová5, Renata Růžková6, \\ Bohuslav Procházka ${ }^{7}$, Jitka Riedlová ${ }^{8}$ \\ ${ }^{1}$ Department of Children and Adolescents, National Institute of Public Health, Prague, Czech Republic \\ ${ }^{2}$ Department of Nutrition, University of North Carolina, Greensboro, USA \\ ${ }^{3}$ Institute of Computer Science, Academy of Science of the Czech Republic, Prague, Czech Republic \\ ${ }^{4}$ Department of Biostatistics and Informatics, National Institute of Public Health, Prague, Czech Republic \\ ${ }^{5}$ Department of Child and Youth Health, 3rd Faculty of Medicine, Charles University, Prague, Czech Republic \\ ${ }^{6}$ Practical Paediatrician, Prague, Czech Republic \\ ${ }^{7}$ Practical Paediatrician, Kutná Hora, Czech Republic \\ ${ }^{8}$ Department of Anatomy, 3rd Faculty of Medicine, Charles University, Prague, Czech Republic
}

\section{SUMMARY}

Growth references are important for paediatric health monitoring. It is critical to understand differences in growth interpretation and potential consequences when using available growth references. This study compares the growth of Czech breastfed children with the current WHO growth standards 2006 and the Czech references 1991, 2001.

A total of $960 \mathrm{infant/parent} \mathrm{pairs} \mathrm{in} \mathrm{the} \mathrm{Czech} \mathrm{Republic} \mathrm{were} \mathrm{recruited} \mathrm{through} \mathrm{paediatric} \mathrm{practices.} \mathrm{Anthropometric} \mathrm{data} \mathrm{were} \mathrm{collected} \mathrm{during}$ infants' first 12 months of life and parent questionnaires were gathered during a preventive visit at 18 months.

Czech breastfed infants were longer with a greater head circumference at all percentiles compared to the WHO standards and were similar to the national references. The percentile weight-for-age and weight-for-length values of infants ( $\leq 6$ months) were lower, and higher ( $6-12$ months) compared to the WHO standards. The infant growth in the sample differed from both the WHO standards as well as the national references.

Our findings indicate that the growth of Czech breastfed children differs from the current national references. These discrepancies were smaller compared to the WHO standards. The results of the study were used for new growth assessment guidelines to optimize feeding recommendations for Czech infants. The adoption of the WHO standards in the Czech Republic is not recommended.

Key words: breastfeeding, Czech, growth standards, infants, national references, WHO standards

Address for correspondence: J. Riedlová, Department of Anatomy, 3rd Faculty of Medicine, Charles University, Ruská 87, 10000 Prague 10, Czech Republic. E-mail: jitka.riedlova@lf3.cuni.cz

\section{INTRODUCTION}

The World Health Organization (WHO) released new growth standards for children aged 0-5 years in 2006 (1). The new standards are based on the Multicentre Growth Reference Study (MGRS) that included a sample of 8,500 children aged 0 to 5 years from 6 countries including Brazil, USA, Ghana, India, Norway, and Oman (2). The main goal of the study was to establish growth standards that could be utilized internationally and thus, serve as a universal assessment tool for growth and development comparisons of children globally $(1,2)$. Growth standards define how children should ideally grow, as opposed to the purpose of growth references that are meant to depict the actual growth of a given infant population. Since 2006, the new WHO standards have been successfully adopted by many countries and have been very useful for growth assessments, especially in nations that have not had appropriate local references available $(3,4)$. However, multiple countries are still in the process of considering the adoption of the new WHO standards and 30 countries have decided not to adopt these standards in their paediatric practice (3).
The Czech Republic is one of a few countries that have had the unique opportunity to utilize its own growth references over the last several decades. The Czech growth references have been constructed and periodically updated based on a long-term and systematic monitoring of the Czech paediatric population (5-7). While the first anthropometric characteristics were collected from 100,000 Czech children back in 1895 (9), the regular Nationwide Anthropological Survey (NAS), with anthropometric measurements from children and adolescents aged 0-18 years, has been conducted every 10 years since 1951 (5-8). Due to the lack of funding in 2011, the NAS was not completed for the first time since 1951. Thus, the 6th NAS completed in 2001 represents the most recent survey of Czech children and adolescents and growth curves from this survey are currently utilized in Czech paediatric practice (10), with the exception of weight-for-age, weight-forheight and BMI-for-age reference values that were derived from the 5 th NAS (6).

Given the unique and long-term anthropometric data from the nationwide surveys, the Czech paediatric practice faced a challenging issue related to the adoption of the new WHO growth 
standards during the past few years. An expert group on growth monitoring, assessment and growth standards was established by the National Institute of Public Health in the Czech Republic after the release of the new WHO standards in 2006. The group recommended to conduct a study that compared the existing Czech growth references, based on a sample of infants included in the NAS, regardless of their nutrition practices in the first months of life (i.e. breastfeeding, and formula feeding), to the WHO standards before the implementation of the new WHO standards would be recommended in Czech paediatric practice.

Czech children were found to be overall longer, starting at birth, than children included in the MGRS study. On the other hand, the values of weight-for-age and weight-for-length in the Czech growth references were similar to the WHO standards, and followed a similar trend to that observed in the sample of children from the MGRS study. The head circumference of Czech infants was found to be greater compared to the MGRS infants (11).

The growth discrepancies described above led the expert group to a decision to conduct further research with the goal of providing additional data and help public health officials decide whether replacement of the existing Czech growth references with the WHO growth standards would be advantageous for Czech paediatric practice. According to the Institute of Health Information and Statistics of the Czech Republic, $40 \%$ of Czech infants were breastfed for $\geq 6$ months and $66 \%$ of birth clinics/hospitals met the WHO criteria for Baby Friendly Hospital in 2011 (12). Given the societal emphasis on breastfeeding and the relatively high rate of breastfed children, accurate growth assessment of Czech infants represents an important and timely issue in this country. Thus the study of the growth of Czech breastfed children was organized. The main purpose of the current study was to compare a sample of Czech exclusively or predominantly breastfed infants to the WHO growth standards 2006. The same criteria as in MGRS were used in selecting the sample of Czech breastfed children.

\section{MATERIALS AND METHODS}

\section{Design, Subjects and Procedures}

This longitudinal study was conducted according to the guidelines outlined by the Declaration of Helsinki. All study procedures involving human subjects were approved by the Ethics Committee of the Third Faculty of Medicine, Charles University prior to any data collection. The study utilized longitudinal data collected between April 2009 and May 2010.

A total of 43 paediatricians around the Czech Republic volunteered to participate in the study and to serve as primary points of data collection during a mandatory health examination of infants at 18 months of age. During the visit, paediatricians explained the purpose and details of the study to parents and asked volunteers to sign a written informed consent form for their and their child's participation in the study. After having signed the consent form, a scripted interview was conducted with each parent with the goal of obtaining detailed data related to socio-economic status, breastfeeding duration and infant age of complementary food introduction. The information was collected by the paediatricians using a standard questionnaire. Additional information was also obtained from infants' vaccination and health records containing their anthropometric measurements from all previous visits, including measurements at birth. All children in the Czech Republic are expected to pass a total of 11 examinations from the birth to the age of 18 months (at birth, 2-3 days after a hospital discharge, at 2 weeks, 6 weeks, 3 months, 4 months, 6 months, 8 months, 10 months, 12 months, and 18 months). In our sample $87 \%$ of infants' data were completed from $\geq 10$ measurements and $13 \%$ from $<10$ measurements.

Low number of the growth data was collected from the children at the age between 12 and 18 months. This trend could be explained by the fact that in the Czech Republic a health examination is not currently mandatory during the infant's $12-18$ months of life. Because of these missing data, growth curves for the age 12-18 months could not be reliably constructed. Therefore, only growth curves for infants aged $0-12$ months were constructed for the purpose of the current study to compare the Czech breastfed infants' growth patterns to the WHO standards.

Data from a total sample of 1,775 children were collected by paediatricians. In order to compare the samples, the same criteria as in MGRS were used in selecting the sample of Czech breastfed children (Table 1). A total of 960 infants (471 boys and 489 girls) with complete data met the inclusion criteria and thus were selected for the current study.

Three percentile curves were used to compare the growth characteristics of Czech breastfed infants to the WHO growth standards (3rd, 50th, 97th percentile). In Czech paediatric practice, these percentile curves have been utilized for assessment of inadequate $(<3$ rd percentile) and/or excessive $(\geq 97$ th percentile $)$ growth $(6,10)$. Because the percentile curves in relation to the WHO standards were nearly identical for both genders, only values for boys were discussed and presented in this study.

\section{Statistical Analysis}

Data collected during the health examinations were carefully checked for anthropometric quality (e.g. an individual growth curves were constructed and examined for every child and each measurement) and individual cases were excluded from the final analysis if unusual values were detected. Final data were processed using a nonparametric model called the Generalized Additive Models for Location, Scale and Shape (GAMLSS) (13). The GAMLSS model represents a widely used group of generalized linear models (GLM), generalized additive models (GAM), and LMS method. GAMLLS was utilized in the development of the new WHO growth standards (15). Furthermore, the BoxCox-power-exponential method with cubic splines was selected for constructing the WHO growth curves (13-15).

In addition to the inspection of concrete absolute values and z-scores, an (approximate) statistical test based on the z-scores (taking WHO or Czech reference as fixed) can be done. Monthly z-scores can be examined separately considering smallest sample size. This conservative approach gives z-scores larger than about 0.33 as significant. For additional z-score analysis, only values corresponding to the 50th percentile for length, weight and head circumference of Czech infants were compared to the WHO standards and to the current Czech growth references. Z-scores for height-for-age, weight-for-age, head circumference, and weightfor-height were computed using the WHO Anthro Programme (version 3.1.0) (16). Similar procedures were followed when the 
Table 1. A Comparison of inclusion criteria for infants in the MGRS study and Czech infants in the sample of Czech breastfed children

\begin{tabular}{|l|c|c|}
\hline Inclusion criteria & MGRS infants & Czech infants \\
\hline $\begin{array}{l}\text { Socioeconomic status not constraining growth (low infant mortality rate, }<5 \% \text { prevalence } \\
\text { of stunting, wasting, and underweight at 12-23 months of age) }\end{array}$ & yes & yes \\
\hline Low altitude $(<1,500 \mathrm{~m})$ & yes & yes \\
\hline Low mobility of the target population & yes & yes \\
\hline Minimum of $20 \%$ of mothers willing to follow feeding recommendations & yes & yes \\
\hline Existence of breastfeeding support system & yes & yes \\
\hline Minimum of a maternal high-school degree & no & yes \\
\hline Non-smoking mother before and after delivery & yes & yes \\
\hline Single full-term birth & yes & born at term excluded \\
\hline Low-birth-weight $(<2,500 \mathrm{~g})$ & born at term not excluded & yes \\
\hline Exclusively/predominantly breastfed for $\geq 4$ months & & yes \\
\hline
\end{tabular}

50th percentile values of all measurements were compared to the Czech growth references using the RustCZ software (17).

\section{RESULTS}

The type of feeding received by the Czech infants by month is presented in Figure 1. At 4 months of age, $92.2 \%$ of the sample were exclusively breastfed (only breast milk and vitamin drops). The rest of the infants were predominantly breastfed (only water or other non-dairy liquids in addition to otherwise exclusive breastfeeding). Approximately $73.3 \%$ of the infants were exclusively breastfed at 6 months of age, with $9.9 \%$ predominantly breastfed and $13.0 \%$ partially breastfed (i.e. mixed feeding with breast milk and other sources of energy and nutrients). At 6 months, 3.8\% of the sample was not breastfed at all. At 12 months, $64.8 \%$ of the infants continued to be partially breastfed.

The length of the infants (Fig. 2) in the study was greater compared to the WHO growth standards starting at birth. The length difference at birth was approximately $1 \mathrm{~cm}$, with greater differences at 12 months at the 50th and 97th percentiles (1.4 $\mathrm{cm}$ and $1.8 \mathrm{~cm}$, respectively). At the $3 \mathrm{rd}$ percentile, the length values were lower compared to the WHO standards between 2 weeks and 3 months.

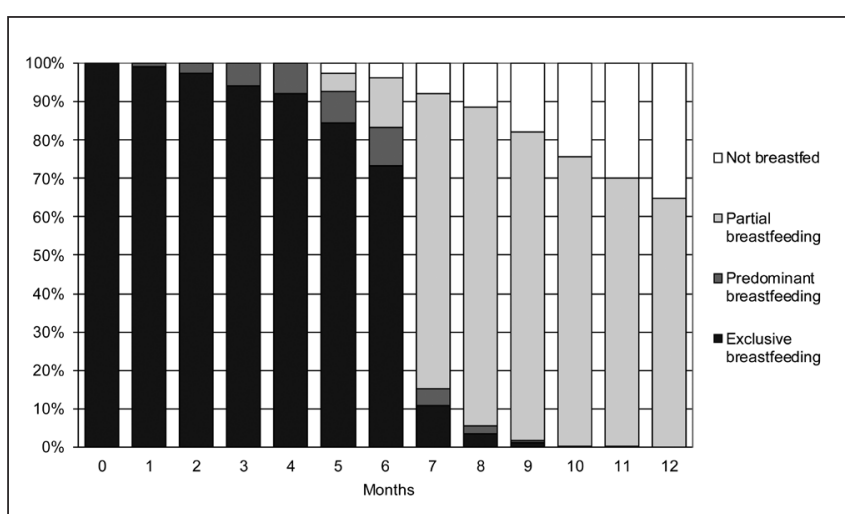

Fig. 1. Breastfeeding rate of Czech infants by months categories.

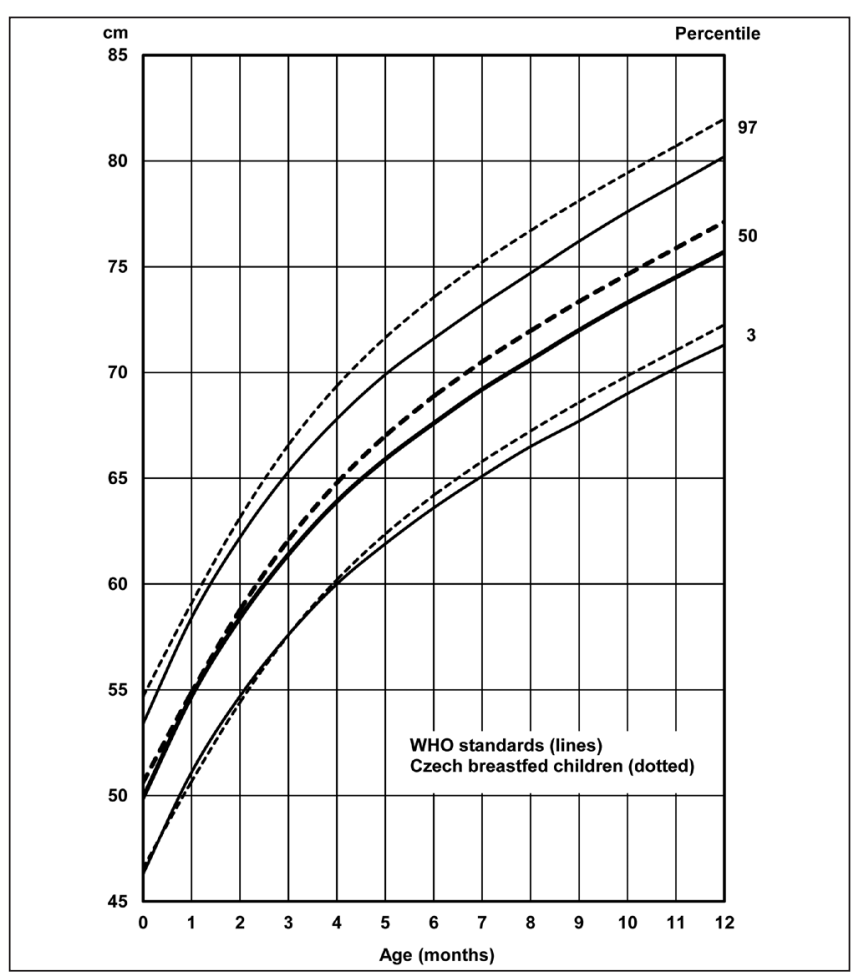

Fig. 2. A comparison of length-for-age values between the WHO standards and Czech breastfed children.

Figure 3 presents the percentile values for weight-for-age of the Czech breastfed infants compared to the WHO standards. The values at the 50th percentile of the Czech infants were consistently but slightly below the WHO growth curve only up to 7 months of age. Between 7 and 12 months of age, the percentile weight-for-age values were higher compared to the WHO values. Even greater differences in weight-for-age were detected at the 3rd and 97th percentiles, with 300-430 g differences at the 3 rd percentile between 4 and 6 months of age. The findings indicated that the Czech and WHO growth curves did not match until 11 months of age at the 3rd percentile and 7-8 months at the 97 th percentile.

Weight-for-length values of Czech infants (up to $70 \mathrm{~cm}$ ) were lower compared to the WHO growth standards (Fig. 4). The largest 


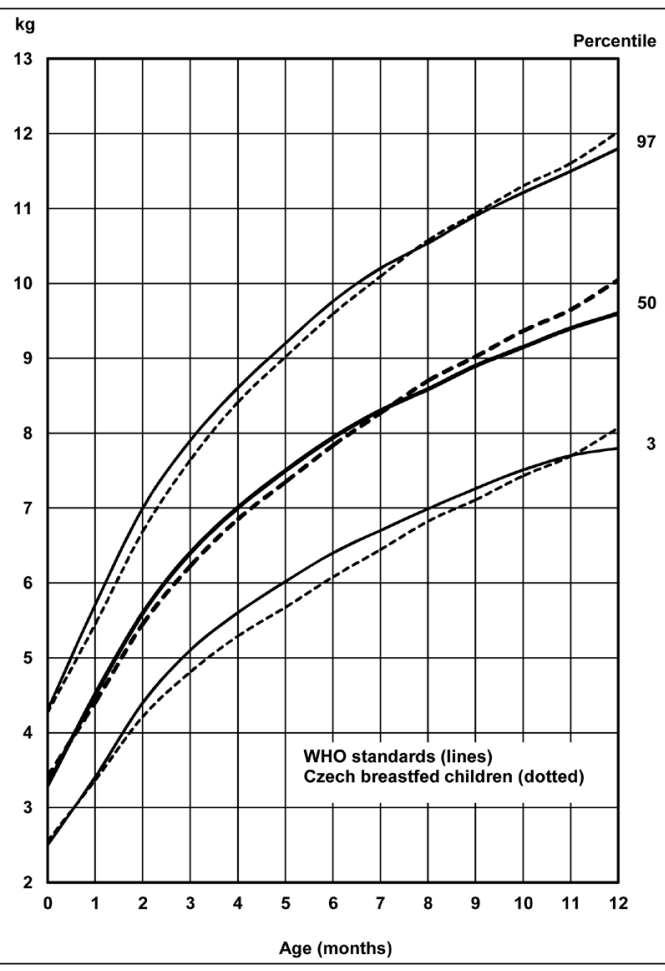

Fig. 3. A comparison of weight-for-age values between the WHO standards and Czech breastfed children.

differences were observed in infants with length of 60-70 cm (400 $\mathrm{g}$ difference in weight). At the $3 \mathrm{rd}$ percentile, the differences were as high as $760 \mathrm{~g}$. Approximately between $55-70 \mathrm{~cm}$, the WHO growth curve at the 3 rd percentile exceeds the values of the 10th percentile in the Czech breastfed infants and even approaches the values of the 25th percentile in Czech breastfed boys. At 70-75 $\mathrm{cm}$ of length, the percentile growth curves crossed, thus indicat-

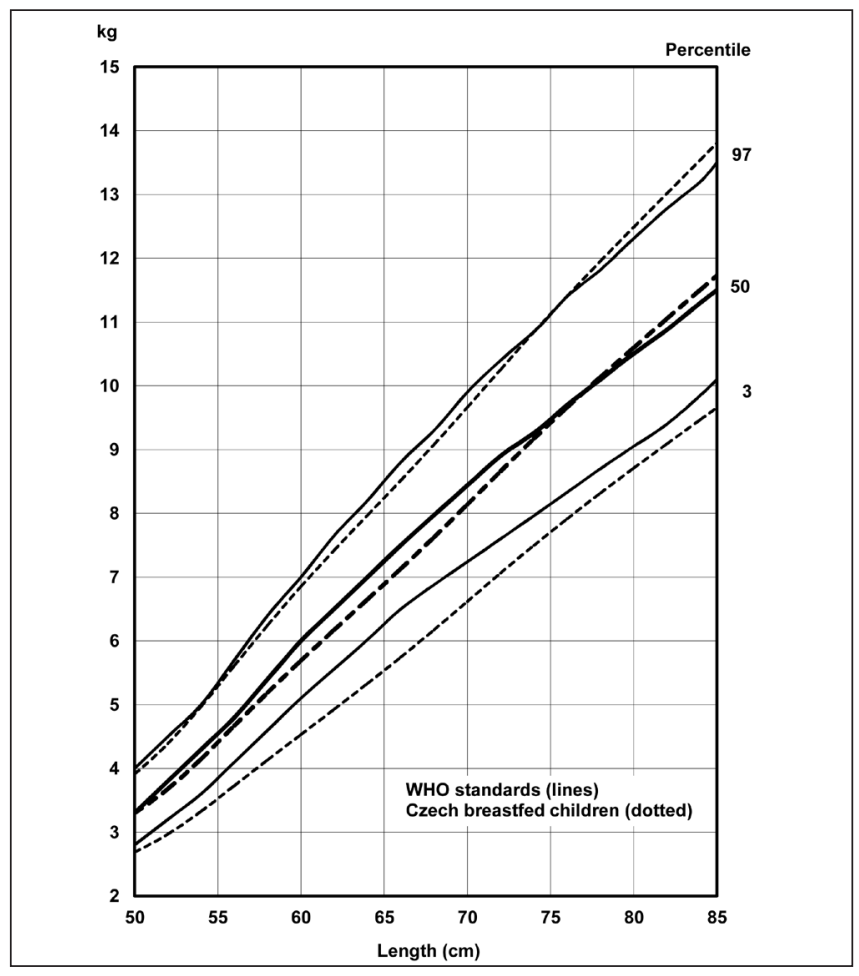

Fig. 4. A comparison of weight-for-length values between the WHO standards and Czech breastfed children. ing that the weight-for-length of the Czech breastfed infants was relatively high compared to the WHO standards.

Additionally, the head circumference of the Czech infants was larger by $5 \mathrm{~mm}$ at birth compared to the infants involved in MGRS. This trend was consistent over time and led to a head circumference difference of $1 \mathrm{~cm}$ at 12 months at the 3rd, 50th as well as the 97 th percentiles.

The values of the Czech breastfed infants for all measures (length-for-age, weight-for-age, weight-for-length, head circumference-for-age) at the 50th percentile, expressed in z-scores, differed from the WHO standards (Fig. 5). The birth data, with the exception of weight-for-length z-scores, were greater among Czech infants. Length-for-age and head circumference-for-age $\mathrm{z}$-scores were similar after the first month of life, however, these values have gradually increased thereafter. After the first 6 months of age, length-for-age values reached a value of 0.6 and remained relatively constant until the age of 12 months. The head circumference $z$-scores increased at a regular rate up to the value of 0.8 at 12 months. Weight-for-age values of the Czech infants differed to the smallest degree from the WHO standards, with the values being slightly below the WHO standards up to 7 months of age with a gradual rise after that. The weight-for-length values of the Czech infants were consistently below the WHO standards between 0 to 11 months.

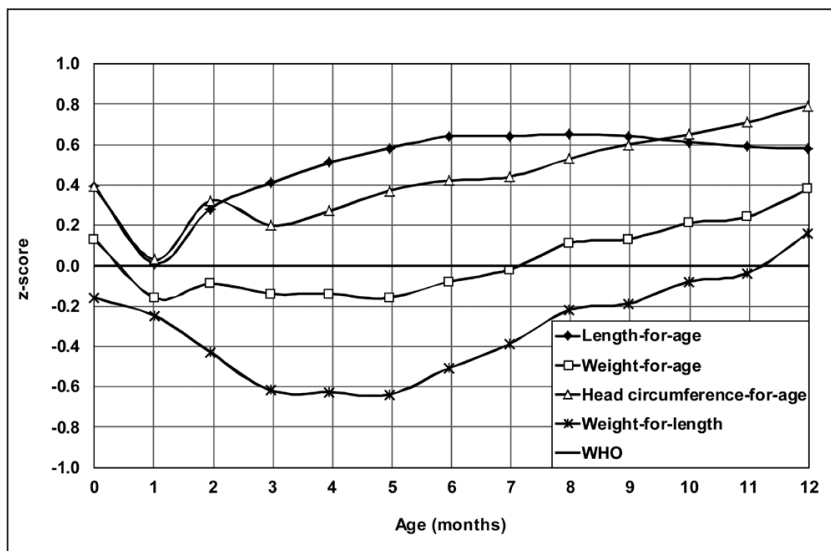

Fig. 5. Growth parameters of Czech breastfed infants expressed in z-scores of the WHO standards.

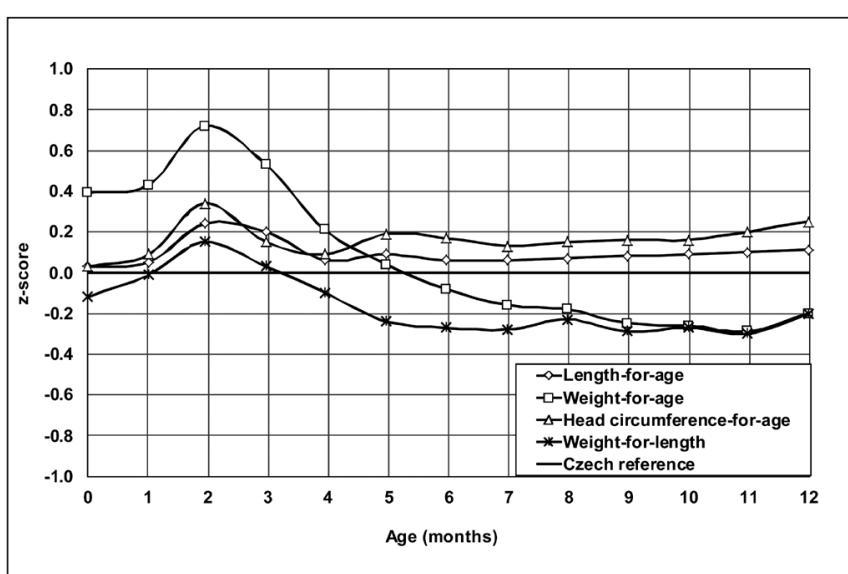

Fig. 6. Growth parameters of Czech breastfed infants expressed in z-scores of the Czech references. 
When compared to the current Czech growth references, the growth of exclusively breastfed infants was significantly greater in the first 2 months of life (Fig. 6), with a relative decrease in growth rate in the following months. Length-for-age z-scores were slightly higher between 4 and 12 months and remained around the value of 0.06 . Similarly, the head circumference $z$-scores were stable starting at 3 months, reaching values around 0.15 .

Data from all anthropometric measures that were collected, including head circumference, indicated that breastfed infants in our sample grew faster up to the age of 2 months with a subsequent relative decline in growth thereafter compared to the existing Czech growth references. Weight-for-age z-scores at 6 months were negative and continued to decline until 11 months of age. Lastly, weight-for-length $\mathrm{z}$-scores were also negative $(-0.25)$ starting at 4 months of age.

Taking into account the approximate (conservative) approach, we took z-scores larger than 0.33 , in absolute value, as indicating significant differences from a standard under consideration. The results showed that values of the 50th percentile of the lengthfor-age values of the Czech breastfed infants were significantly different from the WHO standards between 3 and 12 months of age, weight-for-length values were significantly different between 2 and 7 months and head circumference values differed significantly between 5 and 12 months (Fig. 5). When these values were compared with the existing Czech national growth references, the only statistically significant difference was found in weight-forage from 0 to 3 months of age. Difference of the 50th percentile values of all other body characteristics in all age categories were statistically non-significant (Fig. 6).

\section{DISCUSSION}

The main purpose of the current study was to examine differences and similarities in growth of the Czech breastfed infants in comparison with the 2006 WHO growth standards and the Czech national growth references. The need for the current study arose after the previous research had found important differences in the course of the percentile growth curves between the WHO standards and the currently utilized national growth references in the Czech Republic (11).

The findings of our study indicate that Czech breastfed infants follow a different pattern of growth than infants included in the MGRS study (15). While the growth of Czech breastfed infants differs somewhat even from the current Czech references (6, $10)$, these differences were, in absolute values and in the form of Z-scores, smaller than the differences in relation to the WHO standards. Given the strong public health emphasis and the increasing rates of breastfeeding, the current study adds important knowledge on growth patterns of breastfed infants in the Czech Republic.

To date, a number of studies have examined the impact of the implications of the WHO growth standards on growth assessment or specific nutrition-related outcomes, such as obesity, in other countries (18-24). For instance, examinations of growth patterns among British children were conducted by the Expert Group on Growth Standards of the Scientific Advisory Group on Nutrition and Royal College of Paediatrics and Child Health $(25,26)$. First, the WHO standards were adopted from 2 weeks to 24 months with the use of the United Kingdom 1990 growth references after the age of 2 years (25). More recently, the Royal College of Paediatrics and Child Health developed new growth charts using the WHO standards for use in children from 2 weeks to 4 years of age. Because British infants have higher birth weight than infants in the MGRS dataset, British 1990 birth data were preferred and recalculated for use in the new UK-WHO growth standards $(25,26)$.

The WHO standards were adopted for children aged 0 to 24 months by some countries, including USA and Australia $(19,27)$. Concerns about utilizing the WHO growth standards for children aged 2 and older in Australia, a country without available local growth references, have been also recently expressed (28).

Our results are consistent with studies from several countries where the adoption of the WHO standards has been considered in recent years but not recommended to fully replace the existing national growth references. For instance, a study of a large sample of children in Belgium and Norway found substantial difference between the local references and the new WHO standards (4, 29). The adoption of the $2006 \mathrm{WHO}$ growth standards was thus not supported and local growth references have continued to be utilized in the respective countries (29).

In a study by Rollan-Cachera and Peneau (30), the WHO standards were compared to growth references in France, USA, Netherlands, Belgium, and the United Kingdom. For the first 3 months of life, all country-specific references showed lower values for weight and length compared to the WHO standards. After 6 months of age, country-specific reference values were generally higher than the WHO standards. This study provides more evidence that in addition to the infants in the Czech Republic, children in other countries do not follow the growth pattern outlined by the 2006 WHO standards as well. As Rolland-Cachera and Peneau (30) point out, the type of growth reference utilized has a direct effect on the interpretation of the child's growth in paediatric practice. Therefore, it is critical for paediatricians to be aware of differences between the available growth references and growth standards and realize potential consequences of the growth assessment on specific feeding recommendations (30).

The growth curves in the current study showed that Czech breastfed infants are uniformly longer at all ages and at all percentiles compared to the WHO growth standards; yet the values are consistent with the currently used Czech growth reference values. Similarly, the infant's head circumference values are greater at all percentiles than the WHO standards, but identical to the Czech growth references $(6,10)$. Thus, the implementation of the WHO growth standards among Czech breastfed infants could lead to a variety of consequences, similar to those reported in previous studies $(19,30)$. For instance, a greater number of Czech infants aged $0-5$ months would be classified in the category of "wasting" (i.e. under the $3 \mathrm{rd}$ percentile for weight-for-length) (31). On the other hand, our finding that breastfed infants have a greater weight gains in their first 3 months of life compared to the national growth references is consistent with the results of the MGRS study. After that period the relative decrease in weight gain among breastfed infants occurs when compared to the national growth reference values (Figure 6). This result is essential for the support of longterm breastfeeding. So it is our task to convey this information to Czech paediatricians as well as to parents.

The transition from the Czech references to the WHO standards would be difficult because none of the Czech references 
follows the patterns of the WHO growth standards. As a result, relatively sudden and substantial differences in children's growth assessments would occur during the transition. Lastly, the implementation of the new WHO standards would be challenging due to practical reasons that were highlighted in the previous work, such as time and cost demands of in-depth training necessary for health professionals and new approaches to convey the results to parents (32). Thus, the decision to revise the existing growth assessment guidelines in the light of the findings presented here was a compromise between the utilization of the prospective (WHO growth standards) and descriptive (Czech national references) growth charts.

The current study confirmed that the growth of Czech breastfed infants is specific and differs from the growth of other infants and the type of feeding needs to be considered in growth assessments. While the local growth references are preferred over the new WHO standards in the Czech Republic, it should be acknowledged that the 2006 WHO growth standards still represent an important tool for growth comparisons in paediatric samples across nations, for comparisons of country-specific references to the global growth norm for breastfed children, and are especially useful in countries without local growth reference data (29).

\section{CONCLUSION}

One of the WHO major focus areas is a promotion of longterm breastfeeding, in part because breastfeeding represents an important protective measure against obesity. The WHO growth standards 2006 clearly point out the fact that breastfed infants have a very unique and specific pattern of growth and development compared to other infants. Our findings from the representative sample of Czech breastfed infants indicate that it is not possible to automatically adopt the WHO standards into paediatric practice in the Czech Republic. While the growth of Czech exclusively breastfed infants differs somewhat from the current national references, it differs more significantly from the WHO growth standards.

The implementation of the WHO standards would be extremely challenging in the Czech Republic not only due to large financial and organizational costs, but especially due to different growth patterns of the Czech breastfed infants. Our study has significant practical implications in the area of public health especially for paediatricians who routinely recommend feeding to parents based on growth assessments. Thus, new growth assessment guidelines have already been provided to paediatricians in the Czech Republic (32). The new guidelines contain, among others, the following important information and specific recommendations based on the findings of the current study: Exclusively breastfed infants gain weight faster in the first few months of life compared to the Czech national reference of weigh-for-age values. It is important to be aware of the relative decrease in weight gain among breastfed infants around the age of 3 months, when compared to the national growth reference values, in order to avoid premature introduction of supplemental feeding at this critical time. The existing Czech references for length-for-age and head circumference-for age can be utilized for assessment of growth in Czech breastfed children immediately without any adjustments.

\section{Acknowledgements}

This research study was supported by the Internal Grant Agency of the Ministry of Health of the Czech Republic (grant No. NS 9974-4/2008) and by the Research Programme of the Charles University in Prague (PRVOUK P02).

\section{Conflict of Interests}

None declared

All study procedures involving human subjects were approved by the Ethics Committee of the Third Faculty of Medicine, Charles University prior to any data collection.

\section{REFERENCES}

1. World Health Organization, Multicentre Growth Reference Study Group. WHO Child Growth Standards: length/height-for-age, weight-for-age, weight-for-length, weight-for-height and body mass index-for-age: methods and development [Internet]. Geneva: WHO; 2006 [cited 2014 Sep 24]. Available from: http://www.who.int/childgrowth/standards/ technical report/en/.

2. de Onis M, Garza C, Victora CG, Onyango AW, Frongillo EA, Martines J. The WHO Multicentre Growth Reference Study: planning, study design, and methodology. Food Nutr Bull. 2004 Mar;25(1 Suppl):S15-26.

3. de Onis M, Onyango A, Borghi E, Siyam A, Blössner M, Lutter C; WHO Multicentre Growth Reference Study Group. Worldwide implementation of the WHO Child Growth Standards. Public Health Nutr. 2012 Sep;15(9):1603-10.

4. Roelants M, Hauspie R, Hoppenbrouwers K. Breastfeeding, growth and growth standards: performance of the WHO growth standards for monitoring growth of Belgian children. Ann Hum Biol. 2010 Jan-Feb;37(1):2-9.

5. Prokopec M. Forty years of monitoring child growth in the Czech Republic: methodologies, outcomes and comparisons. In: Eiben OG, editor. Auxology '94. Children and youth at the end of the 20th Century: Invited and selected papers from the 7th International Congress of Auxology; 1994 Jun; Szombathely, Hungary. Budapest: ITC Plantin; 1994. p. 231-70.

6. Lhotská L, Bláha P, Vignerová J, Roth Z, Prokopec M. 5th nation-wide anthropological survey of children and adolescents 1991 (Czech Republic): anthropometric characteristics. Prague: National Institute of Public Health; 1993.

7. Bláha P, Vignerová J, Riedlová J, Kobzová J, Krejčovský L. 6th all-state anthropology investigation of children and youth 2001. Cesk Slov Pediatr. 2003;58(12):766-70. (In Czech.)

8. Kobzová J, Vignerová J, Bláha P, Krejčovský L, Riedlová J. The 6th nationwide anthropological survey of children and adolescents in the Czech Republic in 2001. Cent Eur J Public Health. 2004 Sep;12(3):126-30.

9. Matiegka J. Somatology of schoolchildren. Prague: Nakladatelství české akademie věd a umění; 1927. (In Czech.)

10. Vignerová J, Riedlová J, Bláha P, Kobzová J, Krejčovský L, Brabec M, et al. 6th nation-wide anthropological survey of children and adolescents 2001, Czech Republic: summary results. Prague: Faculty of Science and National Institute of Public Health; 2006.

11. Paulová M, Vignerová J, Lhotská L, Hrušková M. The Risk of accepting new standard of the World Health Organization for evaluating growth of the Czech child population ( $0-5$ years of age). Cesk Slov Pediatr. 2008;63(9):465-72. (In Czech.)

12. Activity in branch of out-patient care for children and adolescents in 2012. Aktuální informace ÚZIS ČR. 2013;(26):1-10. (In Czech.)

13. Rigby RA, Stasinopoulos DM. Generalized additive models for location, scale and shape. J R Stat Soc Ser C Appl Stat. 2005 Jun;54(3):507-54.

14. Rigby RA, Stasinopoulos DM. Using the Box-Cox distribution in GAMLSS to model skewness and kurtosis. Stat Modelling. 2006;6(3):209-29.

15. WHO Multicentre Growth Reference Study Group. WHO Child Growth Standards: growth velocity based on weight, length and head circumference: methods and development [Internet]. Geneva: WHO; 2009 [cited 2014 Sep 24]. Available from: http://www.who.int/childgrowth/standards/ velocity/technical_report/en/. 
16. World Health Organization. WHO Anthro [Internet]. Version 3.2.2. Geneva: WHO; 2011 [cited 2014 Sep 24]. Available from: http://www. who.int/childgrowth/software/en/.

17. National Institute of Public Health. RustCZ [Internet]. Version 2.3. Prague: National Institute of Public Health; 2011 [cited 2014 Sep 24]. Available from: http://www.szu.cz/publikace/data/program-rustcz-kestazeni?lang $=1$.

18. de Onis M, Garza C, Onyango AW, Borghi E. Comparison of the WHO child growth standards and the CDC 2000 growth charts. J Nutr. 2007 Jan;137(1):144-8.

19. Grummer-Strawn LM, Reinold C, Krebs NF; Centers for Disease Control and Prevention (CDC). Use of World Health Organization and CDC growth charts for children aged 0-59 months in the United States. MMWR Recomm Rep. 2010 Sep 10;59(RR-9):1-15.

20. Maalouf-Manasseh Z, Metallinos-Katsaras E, Dewey KG. Obesity in preschool children is more prevalent and identified at a younger age when WHO growth charts are used compared with CDC charts. J Nutr. 2011 Jun;141(6):1154-8.

21. Monasta L, Lobstein T, Cole TJ, Vignerová J, Cattaneo A. Defining overweight and obesity in pre-school children: IOTF reference or WHO standard? Obes Rev. 2011 Apr;12(4):295-300.

22. Schwarz NG, Grobusch MP, Decker ML, Goesch J, Poetschke M, Oyakhirome S, et al. WHO 2006 child growth standards: implications for the prevalence of stunting and underweight-for-age in a birth cohort of Gabonese children in comparison to the Centers for Disease Control and Prevention 2000 growth charts and the National Center for Health Statistics 1978 growth references. Public Health Nutr. 2008 Jul;11(7):714-9.

23. Willows ND, Sanou D, Bell RC. Assessment of Canadian Cree infants' birth size using the WHO Child Growth Standards. Am J Hum Biol. 2011 Jan-Feb;23(1):126-31.

24. Wright $C$, Lakshman R, Emmett $P$, Ong KK. Implications of adopting the WHO 2006 Child Growth Standard in the UK: two prospective cohort studies. Arch Dis Child. 2008 Jul;93(7):566-9.

25. Joint SACN/RCPCH Expert Group on Growth Standards. Application of WHO Growth Standards in the UK [Internet]. London: TSO; 2007 [cited 2014 Sep 24]. Available from: https://www.gov.uk/government/ publications/sacn-application-of-who-growth-standards-in-the-uk.

26. Wright CM, Williams AF, Elliman D, Bedford H, Birks E, Butler G, et al Using the new UK-WHO growth charts. BMJ. 2010 Mar 15;340:c1140.

27. National Health and Medical Research Council, Department of Health and Ageing. Eat for health: Australian dietary guidelines: providing the scientific evidence for healthier Australian diets [Internet]. Canberra: $\mathrm{NH}$ MRC; 2013 [cited 2014 Sep 24]. Available from: http://www.nhmrc.gov. $\mathrm{au} /$ files nhmrc/publications/attachments/n55 australian dietary guidelines_130530.pdf.

28. Hughes I, Harris M, Cotterill A, Garnett S, Bannink E, Pennell C, et al. Comparison of Centers for Disease Control and Prevention and World Health Organization references/standards for height in contemporary Australian children: analyses of the Raine Study and Australian National Children's Nutrition and Physical Activity cohorts. J Paediatr Child Health. 2014 Nov;50(11):895-901.

29. Júlíusson PB, Roelants M, Hoppenbrouwers K, Hauspie R, Bjerknes R. Growth of Belgian and Norwegian children compared to the WHO growth standards: prevalence below -2 and above $+2 \mathrm{SD}$ and the effect of breastfeeding. Arch Dis Child. 2011 Oct;96(10):916-21.

30. Rolland-Cachera MF, Péneau S. Assessment of growth: variations according to references and growth parameters used. Am J Clin Nutr. 2011 Dec;94(6 Suppl):1794S-1798S.

31. Vignerová J, Paulová M, Shriver LH, Riedlová J, Schneidrová D, Kudlová $\mathrm{E}$, et al. The prevalence of wasting in Czech infants: a comparison of the WHO child growth standards and the Czech growth references. Matern Child Nutr. 2012 Apr;8(2):249-58.

32. Paulová M, Riedlová J, Vignerová J, Schneiderová D. How to assess growth of breastfed infants in the first months of life [Internet]. Prague: National Institute of Public Health; 2011 [cited 2014 Sep 24] . Available from: http://www.szu.cz/uploads/documents/obi/CAV/LETAK.pdf. (In Czech.)

Received November 25, 2014 Accepted in revised form January 12, 2015 